\title{
CAYETANO DA COSTA
}

Por Rafael Cómez

Tras la brillante estela dejada por Juan Martínez Montáñez, Felipe y Dionisio de Ribas, y Bernardo Simón de Pineda, la escuela sevillana de retablistas ingresa en el siglo xvil siguiendo las directrices marcadas por este último maestro y de las que es fiel paradigma el retablo de la iglesia del Hospital de la Caridad. Frente a estos artistas aferrados a la tradición de la centuria anterior se alzan innovadores, a partir del segundo cuarto de siglo, dos grandes figuras que marcarán un hito en la historia del barroco sevillano: Jerónimo Balbás y Pedro Duque Cornejo.

Balbás introdujo una originalísima composición de gran riqueza decorativa en los retablos, combinada con un fascinante juego de perspectiva escenográfica, siendo el gran creador de formas nuevas, que se propagarán en México, donde su estilo alcanza un esplendor inusitado. Duque Comejo, formado en la escuela sevillana y algo más apegado a las formas tradicionales, aporta más novedades en lo ornamental que en la composición, tal como podemos ver en el arco de pabellón utilizado en el remate de algunos de sus retablos y del que hará mayor uso Felipe Fernándex del Castillo, seguidor suyo.

La gran aportación de Jerónimo de Babbás a la evolución de las formas del retablo barroco sevillano consiste en la introducción del estipite, típico soporte de la arquitectura del siglo xvin, que lució en el retablo mayor del sagrario de la catedral hasta principios del siglo pasado, en que fue destruido y del que sólo podemos adivinar su magnitud contemplando el de la Capilla de los Reyes de la Catedral de México, obra genial de Balbás, así como la sillería de coro que proyectó en 1714 para la iglesia de San Juan de Marchena, en Sevilla." Por otra parte, Duque Cornejo introduce innovaciones tales como el arco de pabellón, el mixtilíneo, el baluarte y el estipite-atlante, inspiradas en las formas y motivos decorativos de la arquitectura de principios del siglo xvi, según piensa don Antonio Sancho Corbacho.

Con un seguidor de Duque Cornejo, Fernández del Castillo, un nuevo motivo decorativo, la rocalla, comenzará a utilizarse en los reta-

1 Antonio Sancho Corbacho, Arquilectura barroca sevillana del siglo xvm, Madrid, 1952, pp. 269-272. 
blos. El mayor uso y profusión de la rocalla que, combinada con el estipite, engendra formas sigzagueantes, espléndidas y originalísimas, co. rresponde al artista que nos ocupa, Cayetano da Costa, retablista y escultor, cima del arte hispalense en la segunda mitad del siglo xvir.

\section{EL ARTISTA}

Sabemos que Cayetano Alberto da Costa era portugués ya que en los documentos de la época se le menciona como "el escultor portugués". Según Ceán,

Cayetano Acosta nació en Portugal el año 1711, de donde vino a Sevilla con unos muy ligeros principios de su profesión y comenzó a trabajar por sí, procurando imitar las extravagancias de Cornejo y Balbás, de quienes hay muchas obras en aquella ciudad.2

Consta documentalmente que en 1755 se encontraba en Sevilla realizando la fuente del patio principal de la Real Fábrica de Tabacos de dicha ciudad y en 1756 la estatua de la Fama para el mismo edificio. ${ }^{3}$ $\mathrm{Si}$, como supone Sancho Corbacho, se encontraba en Sevilla por 1750, no consideramos muy segura la afirmación de Ceán acerca de los "muy ligeros principios" de la profesión de Cayetano da Costa, dado que por esta fecha era ya un hombre de edad madura -cuarenta años- que vendría ya formado en su profesión de escultor."

Así pues, imaginamos al artista portugués como un emigrado más en la Sevilla de su tiempo, que con gran esfuerzo y tezón, consigue, después de realizar sus importantes obras de la fábrica de tabacos, una gran reputación en el ambiente artístico hispalense. En Sevilla, el gran artista encontró el medio en donde desarrollar las geniales posibilidades de su personalidad. La ciudad en la que eran famosos Jerónimo Balbás, Luis de Vilches, José Fernando y Francisco de Medinilla, Pedro Duque Cornejo y Felipe Fernández del Castillo, debió producir una honda impresión en el espíritu del portugués que, entusiasmado por las obras realizadas por aquellos ilustres maestros, soñaría llevar a cabo un retablo de la magnitud del de Jerónimo de Balbás en el Sagrario de la Catedral.

2 Juan Agustin Ceán Bermúdez, Diccionario histórico de los mós ilustres profesores de las Bellas Artes en España, Madrid, 1800, 1, p. 2.

s Carrera Sanabria, "Obras desconocidas del escultor Cayetano Acosta", Archivo Hispalense, 1945, p. 27; 1947, p. 393.

- Antonio Sancho Corbacho, op. cit., p. 287. 


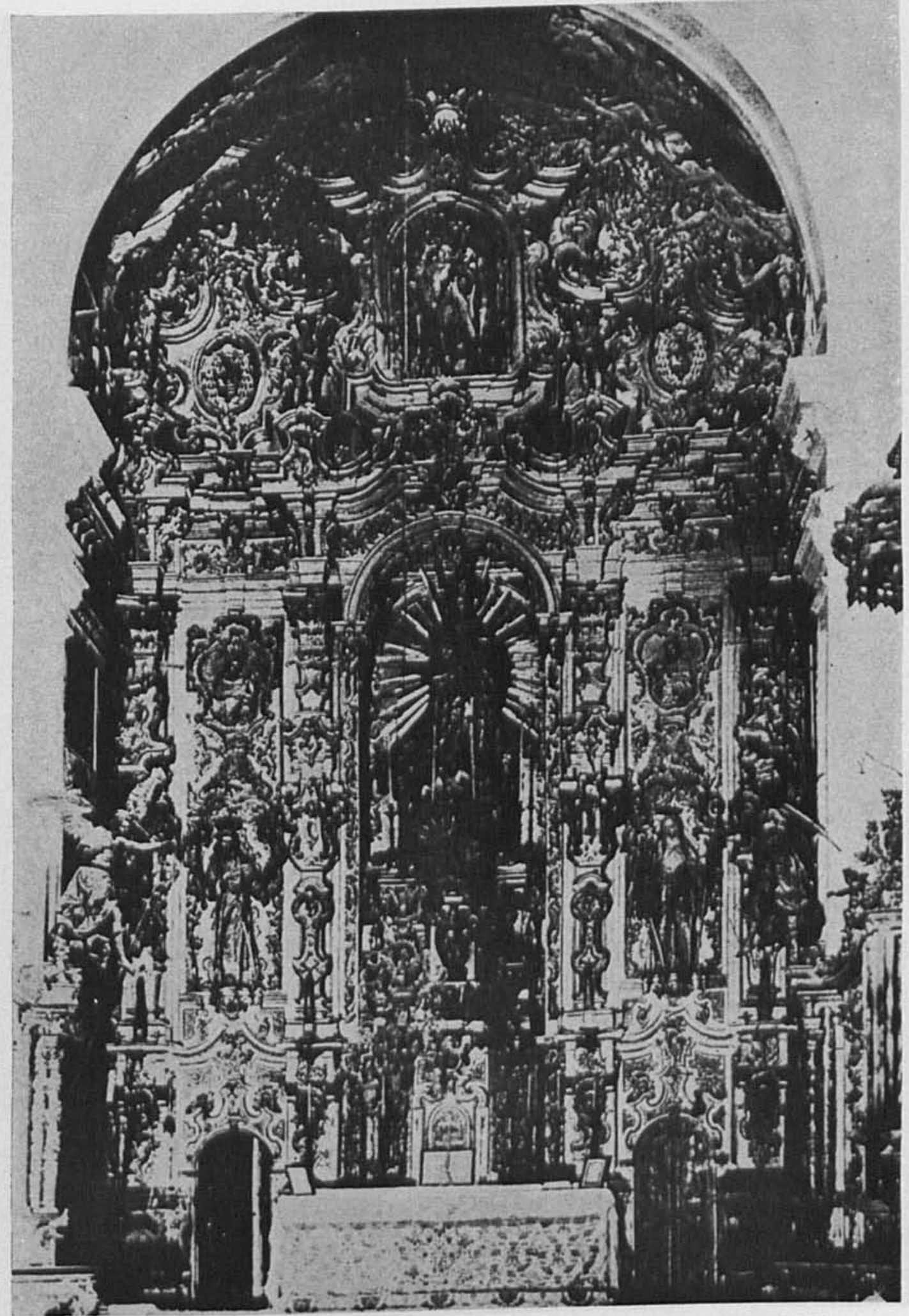

1. Cayetano da Costa. Retablo mayor del convento de Santa Rosalía (1763) Sevilla 


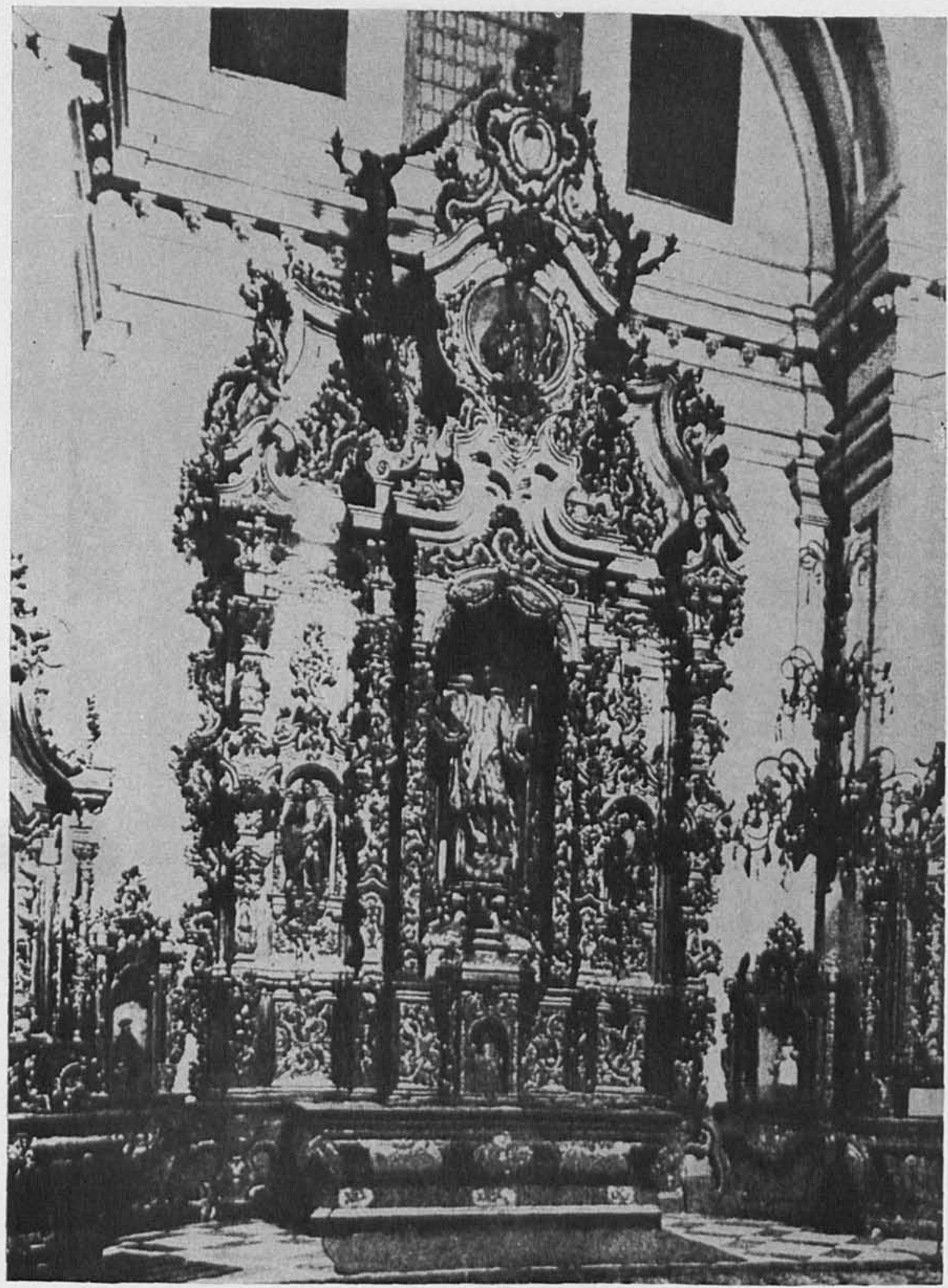

2. Cayetano da Costa. Retablo colateral del convento de Santa Rosalía (1763) Sevilla 


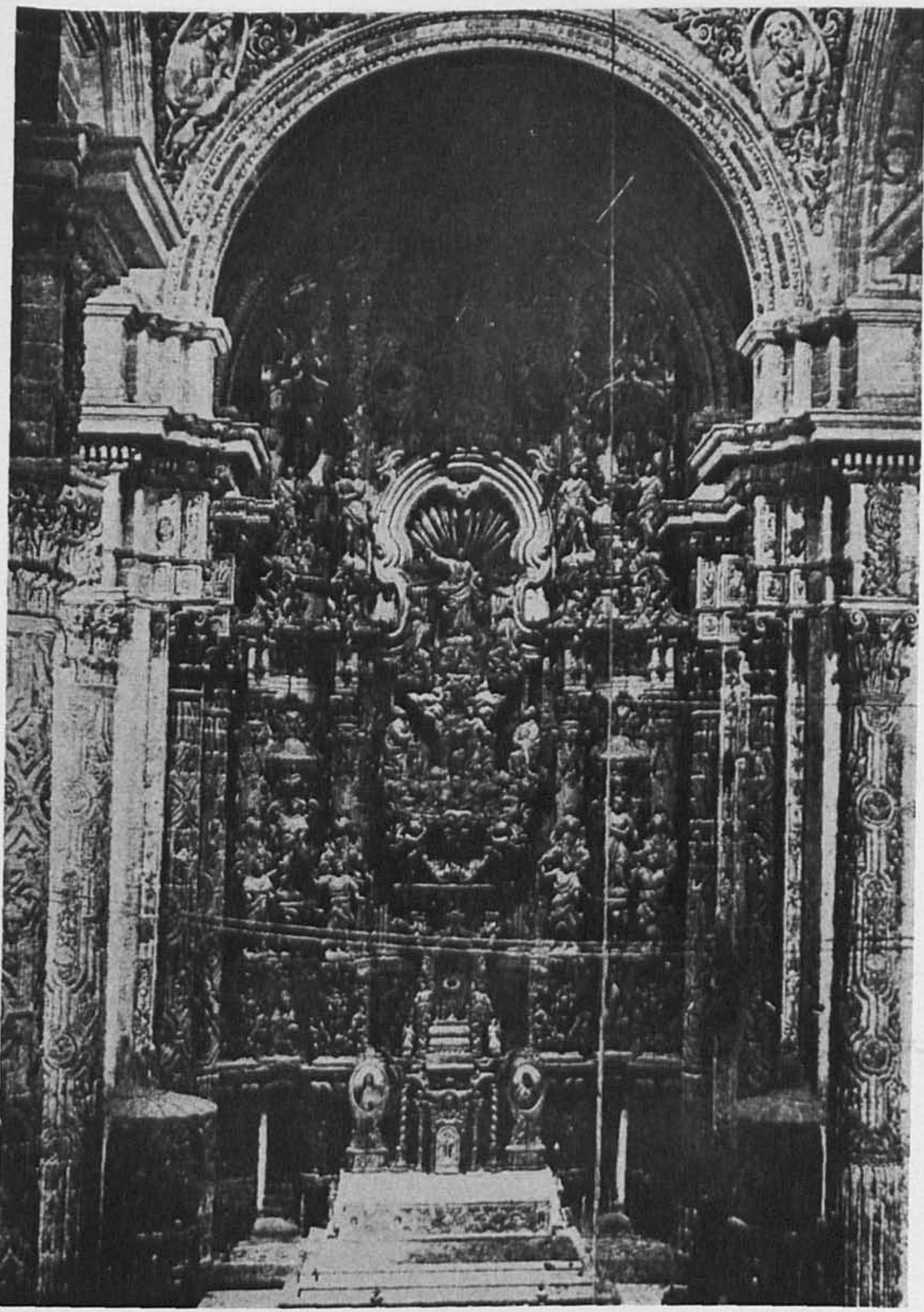

3. Cayetano da Costa, Retablo mayor de la iglesia del Salvador (1770) Sevilla 


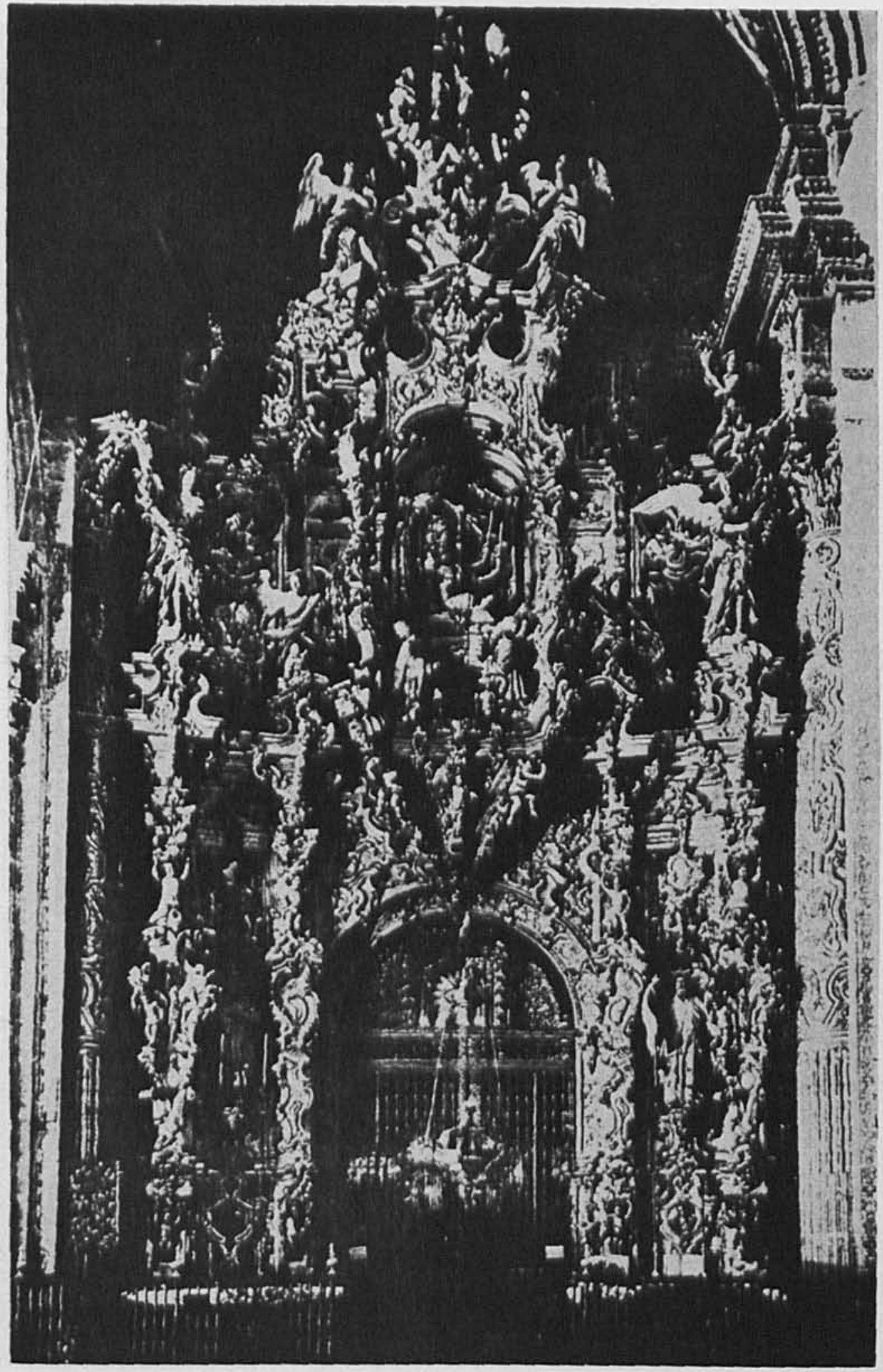

4. Cayetano da Costa. Portada de la capilla sacramental de la iglesia del Salvador (1770) Sevilla 
En la obra de Duque Cornejo y Balbás, seguramente aún más en la de este último, encontraría Cayetano da Costa el reactivo que impulsara su genio escultórico.

En 1767, lo encontramos otorgando un poder en unión de otros artistas sevillanos. ${ }^{5}$ Parece ser que en término de diez años consiguió alcanzar notoria fama en el ambiente artístico sevillano, como:lo demuestra que ya en 1761, tras el incendio del convento de Santa Rosalia, el arzobispo don Francisco Solís y Felch le encarga a su arquitecto, Cayetano da Costa, la realización de siete retablos. Así pues, partiendo de la supuesta fecha de su llegada a Sevilla - 1750-, en diez años, como antes decíamos, consiguió alcanzar una posición social elevada, ya que le vemos como arquitecto del arzobispado, recibiendo importantes encargos.

Esta fama se verfa acrecentada en la década de los años setenta, la última etapa de su vida, puesto que el público prefería sus imágenes a las de Alonso Cano, según se desprende de un recuerdo de Ceán:

Me acuerdo de un devoto que conaci en Sevilla en el año de 1771 y que vendió en el corto precio de $\mathbf{3 0 0}$ reales una hermosísima y graciosa estatua, también de la Concepción, y del tamaño natural, executada en madera por el célebre Alonso Cano, sin otro motivo que por estar en una actitud sencilla y modesta. Para llenar el hueco que ocupaba en el templo mándó hacer a toda costa otra de igual estatura a un portugués mas osado que ignorante, pero de pésimo gusto. Salió la nueva imagen tan movịda y pantomimica con sus contorsiones, y tan galana con su manto revoloteado y guarnecido de encaje de puntas dorado, que llenó las medidas y deseo del liberal devoto y mereció el aplauso de todos los ignorantes que se apresuraban a veria. De estos transtornos hay muchos en los retablos de esta Ciudad executados por Cayetano Acosta, que asi se llamaba el buen portugués. ${ }^{7}$

En otro lugar, hablando de Duque Cornejo, Ceán nos dice que el escultor portugués acabó de propagar el "gusto riberesco" que aquél había difundido por Andalucia. ${ }^{8}$

En 1780, después de ofrecernos su obra maestra en el retablo y la portada de la Capilla Sacramental del Divino Salvador, Cayetano da Costa muere en Sevilla.

B Heliodoro Sancho Corbacho, Documentos para la Historia del Arte en Andalucia, Sevilla, 1934-1946, vi, 96.

6 Antonio Sancho Corbacho, op. cit., p. 287.

' Juan Agustín Ceán Bermúdez, op. cit., II, p. 22.

Ibidem. 


\section{SU OBRA}

La Real Fábrica de Tabacos, Para la Real Fábrica de Tabacos de Sevilla se le encargó en 1755 su primer gran trabajo conocido: la estatua de la Fama, que corona la portada principal de este edificio convertido hoy en Universidad. Se conserva la curiosa carta en que se pormenoriza ámo debe ser realizada dicha estatua. En esa carta, el ingeniero en jefe de las obras, señor Barnola, contesta al superintendente, desde Cádiz, el 28 de septiembre de 1755, en estos términos:

Muy Sr. mio mi amigo: recivo la estimada de $\mathrm{Vm}$. de 24 del corriente y de la misma fha también la de Dn. Sebastian Vanderbercht que me remite los diseños de la Fama y remates que Vm. me dice han acordado con presencia de D. Maximiliano de la Croix, Dn. Joseph de Lozada, del Mtro. Vicente y del Escultor Portugués, con otros inteligentes y de buen gusto y acomodo el mio con el acuerdo de Vmdes; que asi se lo expreso a Dn. Sebastian, haciéndole algunos reparillos de paso que podra manifestar a Vm. sin que estos se separen del principal objeto de la idea.

Le digo qe. La Estatua de la Fama no debe estar vestida, ni con la cabeza cubierta, sino suelto el pelo al uso mugeriego presente, esto es, puesto escarolado, a lo que llamavan (poco haze) a la borrega.

Es impropio cubrirle el pecho con armadura, el que deve descubrir desnudo. con otras cosillas al intento, y otras sobre los remates. Nada de ello perturba el que se conduzca la Piedra y se eche mano a la obra.

Unos meses más tarde, el contador de la obra, don Juan José de Hierro informaba a Juan Antonio Blanco, asentista de "piedra sipia" de Estepa, que Cayetano da Costa salía con un oficial cantero para desbaratar la piedra de la Fama con objeto de facilitar su conducción.? Dada la fecha de esta carta - 14 de abril de 1756- a fines de 1756 estaria ya realizada esta obra, que según podemos ver hoy, fue ejecutada sigtiendo aquellas sugerencias del ingeniero jefe Barnola.

Asimismo, realizó para esta Fábrica de Tabacos, los remates de la fachada y la fuente del patio principal, acabada en 1758.

Los retablos del convento de Santa Rosalía. Incendiada la iglesia del convento de Santa Rosalia, el arzobispo don Francisco Solís y Felch encargó a Cayetano da Costa siete retablos: el mayor, dos laterales y cuatro pequeños para los machones, así como unas vitrinas sobre consolas que se sitúan en los ángulos del crucero. En tres años realizó esta importante obra.

Ibidem, pp. 27 y s. 
El retablo mayor se asemeja al que Duque Cornejo proyectó para la parroquia de Umbrete. ${ }^{10}$ Sigue el dispositivo tradicional de tres calles y remate en el ático. Los soportes centrales son estipites de piezas, según los denomina Víctor Manuel Villegas, mientras que los laterales se han convertido en auténticos estípites rococó. ${ }^{11}$ La decoración está perfectamente armonizada con los elementos constructivos, destacando las magnificas esculturas sin perjuicio de lo anterior.

Dicho retablo es de una gran riqueza iconográfica; la puerta del sagrario presenta un bajorrelieve con el Cordero Místico. Sobre el tabernáculo, en un pequeño cuerpo se alza una pequeña imagen del arcángel San Miguel, situándose sobre ella la gran hornacina central que cobija a la Inmaculada: En la hornacina del ático, que queda bajo el testón, se encuentra la imagen titular del convento, Santa Rosalia. En la calle correspondiente al lado de la Epístola, Santa Clara y sobre ella un altorrelieve con la efigie de San Antonio de Padua, enmarcado en una moldura rococó. En el lado del Evangelio, se contempla la imagen de San Francisco de Asís y en el altorrelieve a Santo Domingo de Guzmán.

Los retablos laterales son más rococós. En ellos impera la rocalla; los estipites han perdido prácticamente su propia forma. Son retablos deslumbrantes cuya labor menuda parece "propia del cincel de un orfebre", como dice Sancho Corbacho.12 Cayetano da Costa ha sabido dar una nueva y original interpretación del estipite, creando uma forma nueva en la arquitectura de retablos cual es el estipite zigzagueante que alcanzará su máximo desarrollo en el templo del Salvador. Esa geniali. dad en asimilar formas anteriores y devolverlas en otras nuevas, muy propias, hizo que Francisco de la Maza considerase a estos retablos "menos audaces pero tan ricos como los del Salvador, con copetes tan movidos y chinescos que ya no son churriguerescos, sino dacastianos"."18

El retablo del lado de la Espistola ofrece los siguientes elementos iconográficos: un Niño Jesús, que en bajorrelieve adorna la puerta del sagrario cuya parte superior se encuentra coronada por una imagen de San Roque. En la hornacina central una bellisima imagen de Santa Teresa de Jesús. A ambos lados, es decir, en las calles laterales: San

10 Antonio Sancho Corbacho, op. cit., p. 288.

11 Victor Manuel Villegas, El gran signo formal del barroco. Ensayo histdrico del apoyo estipite, México, 1956, p. 135.

12 Antonio Sancho Corbacho, op. cit., p. 289.

13 Francisco de la Maza, Cartas barrocas desde Castilla y Andalucia, México. 1963 , p. 118. 
Joaquín y Santa Ana. En el ático luce un gran medallón con la efigie de un santo franciscano barbado, con capucha y cayado, que no hemos podido identificar.

El retablo del lado del Evangelio está dedicado a santos de la Com. pañía de Jesús: San Francisco Javier en la hornacina central y en las calles laterales, San Estanislao de Ketska y San Francisco de Borja. Coronando el sagrario, se encuentra una pequeña imagen de San Nicolás de Bari. En el medallón del ático, la efigie de un santo obispo franciscano en altorrelieve.

En los retablos de los machones se sitúan las imágenes de Santa Inés, en el lado de la Epístola, y San Luis en el del Evangelio.

Las vitrinas consolas guardan imágenes del Niño Jesús y una Virgen del Pilar, en el lado de la Epístola. En el del Evangelio: Santa Rita, el Niño Jesús y San José.

La portada de la capilla Sacramental y el retablo de la Iglesia del Divino Salvador. Entre 1763 y 1770 realizó Gayetano da Costa esta colosal obra para la Colegiata del Salvador de Sevilla: el retablo mayor y la portada a la capilla sacramental.

Según Sancho Corbacho, la gran portada a la capilla Sacramental es "la obra más representativa de la arquitectura retablista sevillana de la segunda mitad del siglo xvir. ${ }^{14}$

La portada es de colosales dimensiones y consta, como un gran retablo, de tres calles: la central a la que abre el arco semicircular de ingreso y las laterales enmarcadas por zigzagueantes estípites que parecen ascender nerviosamente hasta la bóveda del templo. Estatuas y niños atlantes entre olas de rocalla se elevan hacia el cuerpo superior en el que, bajo rococó baldaquino, se desarrolla la escena eucarística: el candelabro de siete brazos sobre el Arca de la Alianza. Sobre ella el Cordero Místico y en el brazo impar del candelabro un cáliz con la Sagrada Hostia. Postrados a sus pies, Abraham y Melquiades con los panes. Como podemos ver, hay una perfecta simbiosis de elementos del Antiguo y del Nuevo Testamento. Los símbolos que prefiguran la Eucaristía: el candelabro de los siete brazos y el Arca de la Alianza, aparecen fusionados con elementos propiamente eucarísticos como el Cáliz, la Hostia y el Cordero. "Parece como si $\mathrm{Da}$ Costa quisiese hacer gala en ella de su conocimiento de las grandes máquinas escénicas que tan de moda

14 Antonio Sancho Corbacho. Ibidem. 
estuvieron en la corte de Austrias y Borbones". ${ }^{15}$ Alrededor del baldaquino danzan gozosos los ángeles bajo la mirada del Padre. Eterno cuya cabeza ha alcanzado, en ese impulso ascensional, las bóvedas del templo.

El gran retablo mayor fue construido a expensas de dos ricos comerciantes de la ciudad, según nos refiere Llaguno. ${ }^{16}$ En su composición sigue el dispositivo tradicional de $\mathrm{Da}$ Costa, introduciendo, sin embargo; columnas corintias estriadas en lugar de estípites, quizá para no romper la armonia de los órdenes corintios que integran los pilares del templo. En el primer cuerpo, tres hermosos ángeles ocupan cada una de las calles laterales del retablo cuya calle central presenta, como es típico en nuestro artista, el Sagrario y el Manifestador, desapareciendo, en cambio, la hornacina central que es sustituida por la escena de la Transfiguración de Cristo en el monte Tabor.

Da Costa creció un poco la estatura del Señor y lo vistió de oro, que es le única manera de recordar al sol y a la luz (su rostro como el sol: sus vestidos como la luz), añadiéndole refulgentes rayos que brotan de su espalda. Pero ¿cómo diferenciarlo, cómo destacarlo de este remolino de esculturas y de formas? Envolviéndolo en un vigoroso arco moldurado que lo separa de todo el resto. La vista, sin querer, hace centro de esta figura y la aisla de la magia del conjunto. Arriba el Padre señala con su diestra hacia abajo, y ofmos las palabras sagradas: He aqui a mi hijo amado en quien tengo todas mis complacencias...

15 Ibidem, p. 290.

16 Eugenio Llaguno y Amirola, Noticias de los arquitectos $y$ arguitectura de España desde su restauración, Madrid, 1829, w, pp. 70-71. La estética del "bucn gusto" arremetió contra la desbordada fantasía de Cayetano da Costa que huloo de sufrir los denuestos de Ceán Bermúdez y Llaguno. Según este último crítico, dos ricos comerciantes de la ciudad ofrecieron al cabildo de la colegiata del Salvador la construcción de un retablo que cubricse todo el testero del presbiterio hasta la bóveda. "Para el desempeño de esta obra -dice Llaguno- buscaron al escultor portugués Cayetano Acosta, que ya habla dado pruebas en este mismo tiempo de su depravado gusto en la arquitectura y de su transtornada imaginación con otro retablazo, que colocó a manera de portada para entrar en la capilla del Sagrario, en la fachada del crucero del lado del evangelio. Por esta sola máquina que yo no sé describir, mereća el tal Acosta privarle para siempre de trabajar, o a lo menos hasta que encerrado donde se le curase el cerebro, hubiese logrado su entero juicio. Pero los dos comerciantes, que lo tenían tan trastornado como él en materia de bellas artes, creyeron que solo Acosta era capaz de ejecutar una obra de tal tamaño y de tanto empef́o; y sin poner límites á su invención, ni a los gastos, trazó y construyó un retablo, que solamente el del Sagrario de la Catedral de Sevilla (ya no existe, á Dios gracias) y el famoso transparente de la de Toledo pueden competir con él en desatinos". 
¿Quiénes acompañan, quiénes pueden acompañar en las calles laterales, la evaneucencia luminosa del Tabor? Solamente ángeles."17

Otras obras. Resulta evidente que, a lo largo de sus treinta años de estancia en Sevilla, Cayetano da Costa realizaría algunas obras más, aún no identificadas. Entre ellas habría que constar el retablo mayor de la Capilla de San José, ejecutado entre 1762 y $1766 . .^{18}$

Se supone que Da Costa crearía una escuela de entalladores entre los que cabría considerar como colaborador suyo a Julián Jiménez que en 1762 realizó el retablo de la Capilla de la Fábrica de Tabacos. El retablo mayor de la iglesia de San Leandro, de autor anónimo, terminado en 1752 queda dentro de este circulo de artistas cuya obra se relaciona con el estilo de Da Costa. El retablo mayor de la Colegiata de Osuna, el de Santo Domingo de Carmona y la portada del Sagrario del convento de Santo Domingo de Jerez de la Frontera pudieran ser obras del propio Da Costa. ${ }^{19}$

17 Francisco de la Maza, op. cit., p. 120.

18 Antonio Sancho Corbacho, op. cit., p. 290.

10 Ibidem, p. 291. 